\title{
VARYING PAID ANNUAL LEAVE LENGTH IN THE WORLD'S ECONOMIES AND ITS UNDERLYING CAUSES
}

\author{
Izabela Ostoj $^{1, \mathrm{a}, *}$ \\ ${ }^{1}$ Faculty of Economics, University of Economics in Katowice, Poland \\ aizabela.ostoj@ue.katowice.pl \\ *Corresponding author
}

Cite as: Ostoj, I. (2019). Varying paid annual leave length in the world's economics and its underlying causes. Ekonomicko-manazerske spektrum, 13(1), 62-71.

Available at: dx.doi.org/10.26552/ems.2019.1.62-71

\begin{abstract}
Paid annual leave (PAL) is one of the elements of working time regulations. The regulations are implemented at national levels, but core labour standards in this resects are stipulated by the International Labor Organization. The European Union member states are also guided by the relevant directive. Together with the length of the working day and week as well as the number of paid public holidays, the length of annual leave is essential to determine the potential of working time in every economy and the costs of hiring a full-time employee. Under globalization, this may be one of the factors determining business location. From the employees' point of view, the length of paid annual leave is an important element in maintaining a work-life balance. The article aims to examine the differences in the length of paid annual leave between countries and regions in average terms and depending on tenure, as well as to identify the groups of countries and regions where paid annual leave is relatively longest and shortest. It also proposes how the differences in the PAL length can be explained based on Hofstede's cultural dimensions model and legal tradition. The anticipated directions of changes in paid leave regulations are also discussed. Based on the critical analysis of data and information from international organizations, in particular, the World Bank and the International Labor Organization, and existing reference literature, the article provides arguments confirming the thesis that the length of paid annual leave depends on systemic, in particular cultural, factors.
\end{abstract}

Keywords: paid annual leave, labour legislation, labour standards, cultural differences

JEL Classification: J800, F660, P500

\section{Introduction}

The category of paid annual leave (PAL) is one of the elements of working time regulations, yet it comes under scientific scrutiny relatively rarely. Although basic standards in this field are developed by ILO, countries vary significantly in terms of PAL and the underlying causes for these differences do not seem to be fully identified. Apart from the length of the working day and week as well as the number of paid public holidays (PPH), the length of annual leave is essential to determine the potential of working time in every economy and the costs of hiring a full-time employee. Under globalization, this may be one of the factors determining business location. From the employees' point of view, the length of PAL is an important element in maintaining a work-life balance. The article aims to examine the differences in the PAL length between countries and regions in average terms and depending on tenure, as well as to identify the groups of countries and regions where paid annual leave is relatively longest and shortest. 
It also attempts to relate the varying PAL length to cultural determinants. The anticipated directions of changes in the area of PAL regulation and the problems related to compliance with applicable laws will also be discussed. Based on the critical analysis of data and information from international organizations, in particular, the World Bank and the International Labor Organization, and existing reference literature, the article provides arguments confirming the thesis that the length of PAL depends on systemic factors. To show the differences in PAL on a global scale, descriptive statistics were used. The article consists of five parts. Part one discusses the issue of paid annual leave based on reference literature; part two outlines the research method, while part three presents the results of the study. Part four is the discussion on the results relating to potential cultural determinants of differences in the PAL length and part five provides the evaluation of the potential directions in PAL changes illustrated with the examples of selected countries.

PAL related issues are relatively rarely analysed, which may come as a surprise, since the relevant legal provisions constitute important regulations of working time, alongside the length of the working day and week as well as the number of paid public holidays. The degree of compliance with existing regulations is also important. While the length of the working day and week varies negligibly between countries, the length of PAL and its actual use may reveal significant differences. The literature on PAL deals mainly with entitlements, PAL use and the importance of PAL for employees (Skinner and Pocock, 2013; Wooden and Warren, 2008; De Bloom, 2015). From a historical perspective, the introduction of annual leave as one of the standard working conditions undoubtedly manifested progress in relations between an employer and employee, improving the symmetry of those relations and creating opportunities for employee participation in progress, prosperity and improved quality of jobs. While the immediate manifestation of increased labour productivity was a growing average pay, the introduction and extension of PAL were its other aspects, as they represented alternative forms of employee participation in the benefits stemming from improved economic efficiency.

The introduction of mandatory annual leave is credited to ILO, which first regulated the issues related to paid annual leave in Holidays with Pay Convention No. 52 in 1936 - the minimum leave length was set at 6 working days. The current revised Convention No. 132 as of 1970 imposes on the countries that have ratified it the obligation to apply paid annual leave of not less than 3 working weeks for one working year, including two weeks of uninterrupted leave (Articles 3 and 8). The convention was ratified by 37 countries (ILO, Normlex). The Directive 2003/88/EC is also applicable to the EU countries. Article 7 of the Directive stipulates that the EU member states should take the measures necessary to ensure that every worker has the right to paid annual leave of at least four weeks in accordance with the conditions laid down by national legislation and/or practice. Additionally, it is stated that the minimum period of paid annual leave cannot be replaced by an allowance in lieu, except for the situation when the employment relationship is terminated.

Nowadays the importance of PAL is considered in the context of the impact on the balance between professional life and private/family life, employees' long-term health, as well as reduction in sickness-related absenteeism (Skinner and Pocock, 2013; Block et al., 2013; Allen et al., 2014; Lindahl et al., 2015; Oswald et al., 2015). The benefits derived from longer PAL are difficult to measure and can be observed in the longer term, which is the reason why they are under-researched.

The growing importance of PAL is also evidenced by the results of research showing employee preferences regarding the extension of paid leave in relation to pay increases, which were conducted in Australia (Skinner and Pockock, 2013). Employees facing the choice between a pay rise proposal and PAL extension tended to choose the latter option. This testifies 
to the growing importance of free time for employees and the resultant perceived increase in welfare (Gilbert and Abdullah, 2002). However, studies focusing on individual countries and their domestic determinants dominate this research area, comparative analyses are less frequent, although studies reveal that significant differences exist even between highly developed countries (e.g. Block et al. 2013; Bargain et al., 2014). In the global economy, sources of differences in the PAL length remain an important research problem.

Another problem concerns PAL entitlements, which in principle are granted to employees hired based on an employment contract, while they do not embrace civil law contracts or selfemployment (Fakih, 2018). Informal employment is also important, both in the non-formal and informal sectors, which by nature is not covered by any form of protection under labour law, including PAL entitlement. Informal employment can amount to a significant volume and, depending on a country, ranging from a few percentage points to as much as $90 \%$ depending on a region or a country (ILO, 2018). Therefore, in economies with an extensive informal employment sector and a significant proportion of non-standard forms of employment, PAL regulations are of less importance as they affect a smaller proportion of the labour resource. The demands of global competition and the popularity of flexible forms of employment contribute to this situation.

Numerous studies also look into the reasons why employees choose not to take advantage of their PAL entitlement. The main reasons include the desire to accumulate leave days and excessive workload (Skinner and Pockock, 2013). The former may be important especially in the case of relatively short holidays. The latter is usually associated with the dominant work culture. They may both coexist.

\section{Methodology}

In pursuit of the research goals addressed in this article, the author reviewed the World Bank's data included in the Doing Business (service sector) database for 2019, covering four groups - according to work tenure (1 year, 5 years, 10 years) and the mean value of these three values. The basic descriptive statistics were used for general characteristics. Then, based on the data, countries were selected in which the PAL length is the shortest and the longest in three groups and by an average value. The next part is an attempt at the data systematization and evaluation in terms of geographic location and selected system characteristics. Finally, conclusions were formulated.

\section{Results}

The PAL length varies between countries both by tenure and the mean of the three tenure values. Table 1 shows basic descriptive statistics of the PAL length for 200 countries around the world. Somalia was excluded from the calculations (and further analysis) due to the poor credibility of the data.

The calculations show that: 1) the maximum length of annual leave in the world for the three analysed tenure values is slightly different, 2) the arithmetic mean, as expected, increases, but it grows more dynamically when tenure increases from 1 year to 5 years, 3) the median is relatively high, which means that in half of the world's countries PAL is longer than 20 days, 4) standard deviation shows that the length of annual leave after 1 year of work deviates from the mean the most - by approx. 7 days, but in other results standard deviation is similar, it is more than 1 working week, which can be considered significant. 
Table 1: Descriptive statistics on the length of paid annual leave (working days, 2019)

\begin{tabular}{crcccc}
\hline Tenure & Min. & Max. & Arithmetic mean & Median & $\begin{array}{c}\text { Standard } \\
\text { deviation }\end{array}$ \\
\hline 1 year & 0 & 30 & 17.25 & 18 & 6.99 \\
5 years & 0 & 31 & 18.60 & 20 & 6.59 \\
10 years & 0 & 32 & 19.47 & 20 & 6.73 \\
$\begin{array}{c}\text { Average (1, 5, 10 years } \\
\text { of tenure) }\end{array}$ & 0 & 30.3 & 18.45 & 20 & 6.55 \\
\hline
\end{tabular}

Source: World Bank (2019). Author's calculation.

The PAL length for the shortest tenure of 1 year was analysed as the first one. Apart from the extreme case of countries where there is no statutory PAL length (the USA and several small countries such as Gambia, Marshall Islands, Micronesia, Palau, and Tonga), the shortest length of paid annual leave is 5 days. This applies to China and the Philippines ( 5 days) and Liberia (5.5 days). A 6-day annual leave after one-year tenure is granted to employees in Mexico, Nigeria and Thailand. In China, the Philippines, and Thailand, it is not extended after 5 years in employment, as is the case of Nigeria. In Mexico, after 5 years of work, it is extended to 14 days and in Liberia to 22 days. These countries demonstrate a completely different approach to determining the PAL length. Especially in the three above-mentioned Asian countries, short leave is perceived as appropriate. This also applies to the tenure of min. 10 years, the Philippines still only grants five days of PAL, Thailand -6 days (so does Nigeria), in China annual leave extends to 10 days. However, if we take the average PAL length calculated as the arithmetic mean of the three dimensions of PAL length based on tenure, the Philippines has the shortest PAL - 5 days, Nigeria and Thailand - 6 days, China - 6.7 days. As it can be seen, the countries with the shortest PAL length in different perspectives include three Asian countries. In these countries, short paid annual leave can be attributed to "the culture of long working time", which is strong especially in the Southeast Asian countries. A similar phenomenon also occurs in the USA, where hard work ethic is a driver for promotion and social recognition (Messenger and Ray, 2013). Short annual leave in medium terms also concerns Samoa, Trinidad and Tobago (10 days), Singapore (10.7 days) Costa Rica and Ecuador, Guyana, Indonesia, Lesotho, Mexico (12 days), El Salvador (11 days), Jamaica (11.7). Thus, the regular occurrence of short leave in Southeast Asian countries is confirmed. It is not only about the shortest annual leave on a global scale, shorter than ILO recommended, but also about the relatively longest leave in the region - New Zealand grants 20 days of PAL (regardless of tenure), which is the length close to the minimum recommended by ILO. The situation in Latin American countries is slightly different. Most countries have relatively long leaves, while in Mexico and Central America, Costa Rica and Jamaica, PAL is shorter, which should be treated as an exception. In Africa, Nigeria is also an exception in terms of how short PAL is. According to the working time researchers, employers expect significant commitment to work from employees in the Middle East and North African countries (Messenger and Ray, 2013), but this is not manifested in the PAL length, which is relatively long in these countries, which will be discussed below.

The next part of the article presents the countries where PAL is the longest. The longest universal PAL (apart from the special entitlements of certain occupational groups) is 32 days in Congo and 31 days in France (after 10 years in tenure). The longest PAL after 1 year of work is 30 days and is granted in such countries as Bahrain, Djibouti, Finland, France, Guinea, Kiribati, Kuwait, Libya, Maldives, Nicaragua, Togo, and Yemen. As it can be seen, they are located in different regions of the world, but as many as 5 of them are Middle Eastern and North African countries, whose markets are strongly regulated, and the state is the dominant employer. After 5 years of work, only Mozambique joins this group of countries, and after 10 years - 
Bolivia and Egypt. Notably, the countries that have adopted the principle of long annual leave apply it from the first year of work, but a few countries join this group, increasing PAL duration in proportion to longer tenure. As for the arithmetic mean, the longest PAL is granted in France -30.3 days. (Carincross and Waller, 2004)

As mentioned above, the USA is the only highly developed economy important in the world, which has not introduced PAL. In practice, the number of days of annual leave is left as part of a compensation package negotiated between an employer and employee. The average entitlement for workers in the USA is 9-10 days (Ray and Schmitt, 2007; Llewellyn Consulting, 2016). The United States is dominated by the conviction that weakly regulated markets for goods and labour are more effective. The country is, however, immersed in a nationwide debate on the weakness of the employee's position in this respect, compared with other highly developed countries, especially in Europe (Altonji and Usui, 2007; Ray and Schmitt, 2008; Gereffi, 2014). The situation is similar in Canada, where PAL lasts 10 days, regardless of tenure. It is different in the EU countries, but also in many other European countries where the employer's advantage in employer-employee relations is assumed and the need to legally protect the employee's interests is, therefore, recognized. Australia, on the other hand, follows Western Europe in the area of labour market regulations, adopting the length of PAL in 20 days, regardless of tenure (Block et al., 2013).

To a certain extent, the PAL length can be compensated by the number of paid public holidays (PPH). In countries where PAL does not exist or is very short, the situation varies. In the USA, there are no statutory PPH, but employers usually grant leave on public holidays, 6 days a year on average (Llewellyn Consulting, 2016), while no information is available on other countries where PAL does not apply. In China, the Philippines and Liberia, the number of PPH is about 11 days (depending on the year and on how public holidays coinciding with Saturdays or Sundays are treated), so to a certain degree, they complement short paid annual leave. The countries with the largest number of PPH include Cambodia and Iran (27 days) (ILO, Conditions ...). After taking them into account, these countries have the longest paid leave in the world (Cambodia - 45, with one year of tenure, Iran - 51, regardless of tenure). In practice, the number of days off, both PAL and PPH, may vary between countries depending on the economic sector and relevant national regulations. In addition, some countries grant additional leave for specific purposes, for example for civic duty or for moving house in Spain (Ray and Schmitt, 2007). They enable employees to fulfil their basic needs without the use of PAL for this purpose, but they also raise labour costs. The examples provided show that the differences in PPH between countries are significant and should be accounted for in the total burden of costs generated by non-working days incurred by employers.

\section{Discussion}

An interesting research task is to identify the underlying causes of differences in the PAL length occurring between countries. As indicated above, the certain significance is attributed to cultural factors. Extracting their impact is difficult due to the fact, that international standards imposed on the ILO member countries result in a certain approximation of the PAL length and probable deviations from the length that countries would apply to determine the PAL length independently. On the other hand, the number of countries that have ratified the convention regulating the minimum length of PAL is limited (37 countries). Similar significance and still higher standards concerning the PAL length are posed to the EU countries. Their impact may be exemplified by the changes that were implemented in the UK, where no statutory PAL applied and paid annual leave was subject to collective agreements and, in practice, its length 
was on average 20-25 days (ILO, 1995, p. 367). Since 2009, the PAL length in the UK has been 28 days. Before the adoption of the directive regulating the minimum length of PAL in the EU, the EU countries varied significantly in terms of the length of leave guaranteed by law, while collective agreements offered the possibility of PAL extension (Lee et al., 2007).

The discussion of cultural factors as differentiators of the PAL length may lead to the formulation of a few hypotheses based on the results of Hofstede's research, which analysed societies in terms of time orientation, uncertainty avoidance, masculinity, individualism and power distance. As mentioned above, short PAL regardless of tenure is typical of Southeast Asian countries. According to Hofstede (Hofstede et al., 2010; Beugelsdijk, et al. 2017; Kirkman et al., 2017), many of these countries are characterized with long-term orientation (China, Hong Kong, Taiwan, Japan, Vietnam, South Korea, India, Thailand, Singapore) and rank top according to the long-term orientation index. Long-term orientation involves not attaching importance to free time, which may favour the tolerance of short PAL, as opposed to the countries with a short-term orientation. On the other hand, countries with very short statutory PAL also include the countries with short-term orientation, such as Nigeria, the Philippines, Canada, New Zealand, and finally the USA - with no statutory PAL. Thus, longterm orientation is not a sufficient cultural dimension that could account for short PAL. Contrary to commonly held expectations, countries, where PAL is short, are characterized, in their majority (except for Japan), by another cultural dimension - the low uncertainty avoidance index. This may come as a surprise because in cultures with strong uncertainty avoidance people like to work a lot and be constantly engaged. A possible explanation is that in countries with low uncertainty avoidance people do not seek to recognize all rights under rigid rules and assume that they will be able to negotiate additional free days off work with their employer if necessary. In addition, they usually feel healthier and more satisfied with life, so the right to a long vacation may not be so important to them. By contrast, in countries with high uncertainty avoidance, employees strive to secure the right to sufficiently long leave in advance. Another important dimension of national cultures is masculinity-femininity, measured with the masculinity index. Societies with the low masculinity index, referred to as feminine, usually value free time higher than additional pay. Therefore, longer PAL should be expected in societies with the low masculinity index and vice versa. This phenomenon is difficult to discern when we analyse countries according to the length of leave and the ranking according to the masculinity index. It is confirmed in the case of Japan, Mexico, Jamaica, China, USA - the countries with the high masculinity index, while most countries where PAL is short have an average level of this index. A high rate of individualism (USA, Canada) is also conducive to short leave. In this case, individualism is a dimension expressing pro-market orientation and, at the same time, favouring low employee protection (Jong, 2009). However, this is contradicted by short leave in Southeast Asian countries, which are collectivist by nature. Collective-oriented materialism hypothesis (Awanis et al., 2017) can help in the explanation of this phenomenon. It also seems that the low power distance index may favour short PAL, due to the decentralization of decision-making processes and a potentially better possibility of negotiating the length of leave, accompanied by lower expectations of statutory guarantees. To a certain extent, the dimensions of national cultures can, explain the occurrence of differences in PAL length. (Steward and Stanford, 2017)

The effect on differences in PAL length may also be of legal origin. Two main sources of law must be considered - common law and civil law. This division emerged in the 12th century and affected the nature of laws and regulations around the world (Botero et al., 2004; Gregory and Stuart, 2004). In the countries with common-law tradition, such as the UK, the USA, Canada, New Zealand, India, Israel. Pakistan, Southeast Asian countries, annual leave is 
relatively short or the law does not stipulate its length, as is the case in the USA. In the common law system, the role of codes is relatively insignificant, while precedents constitute an important source of law. In the countries with the civil law system, the basic form of legislation is the act of law, while legal regulations tend to be more numerous and detailed (La Porta et al., 2008). In most countries where long PAL is in force, the civil law system is in place. It seems that both national cultures and legal tradition together with their mutual interdependencies may determine the length of PAL.

\subsection{Future of PAL}

In view of the universality of PAL, this solution will certainly remain one of the basic regulations of working time also in the future. However, it is worth looking at the anticipated directions of change. Trade unions may initiate change concerning PAL. One example may be the All-Poland Alliance of Trade Unions proposal for the extension of annual leave from 26 to 32 days announced in 2016, which, however, was not acted on by the government. At the same time, there are countries in the world that adopt PAL for the first time or extend it. In 2018, Kiribati introduced statutory PAL for the first time and made it 30 days long, regardless of tenure. In the same year, Taiwan extended PAL by one day and Canada by five days after 5 years of work in 2019. These examples illustrate the efforts to extend PAL. There are also cases where reforms aimed at shortening PAL were recently implemented, for example, Puerto Rico in 2018, when the PAL length decreased from 15 to 12 days (with tenure of 5 years and more) and to 9 days for the first year of work (World Bank, 2018). However, this is a US dependent territory. Despite this trend, it seems that tendencies to extend PAL are stronger on a global scale. If the labour market became more liberalized, this liberalization might be manifested in a number of ways (Witt and Jackson, 2016), without necessarily involving a reduction in the PAL length. What could change is how PAL is enacted. With increased importance of collective bargaining at the enterprise level, PAL can become the subject of collective agreements. This might lead to the emergence of differences in the PAL length between employees of various industries and even enterprises (Cairncross and Waller, 2004).

Nevertheless, certain threats to employee rights, including PAL entitlement, related to the development of a gig economy are emerging. It has already been mentioned above that employees working based on civil law contracts or self-employed do not have PAL entitlement. The advancements in modern technologies, especially digital business platforms, systematically increase the share of gig work, i.e. work consisting in carrying out separate tasks, which can be accessed both by independent service providers and buyers through specially designed communication platforms and applications, coordinating business activities in a given business model, e.g. Uber, Foodora (Minter, 2017; Stewart and Stanford, 2017). Business platforms also enable large numbers of freelancers globally to provide their services. This model ensures that the supply of services is effectively matched to the demand for them and, in consequence, leads to reduced operating costs. Within this model, services are usually performed by self-employed or contracted employees, dependent on one client and his terms, while at the same time deprived of basic employee rights, including PAL (Stanford, 2017; Kinderman, 2017). Therefore, there is a risk of the segmentation of the labour market into employees fully benefiting from employee rights, including PAL, and service providers engaged in precarious activities, deprived of these rights. Thus, the development of the gig economy poses new challenges in the area of labour market regulation. 


\section{Conclusion}

Although ILO introduced PAL related standards, as demonstrated above, many countries do not comply with them and differences in the length of PAL between countries remain significant, as shown by, inter alia, descriptive statistics. Different countries adopt different rules for determining the PAL length. In some countries, paid annual leave is very short and does not correlate with tenure, while in others it grows with tenure. These differences can be partially explained by cultural factors and preferred value systems, especially work ethics. In particular, this concerns relatively short PAL in Southeast Asian countries regardless of tenure and the lack of statutory PAL in the USA. Unregulated PAL as an element of working conditions negotiable between an employer and employee, as it is in the USA, attracts increasing criticism.

Relatively long PAL is typical of North African and Middle Eastern countries, which can be associated with the generally highly regulated labour market and the important role of the state as an employer. Long paid annual leave can be also attributed to the nature of industrial relations and the position of trade unions, which is evident in European countries. At the same time, it is difficult to make explicit generalizations in this sphere and they should be formulated with great caution since there are usually exceptions to the rule. The analysis of the PAL length also requires the inclusion of $\mathrm{PPH}$, which may change the perception of employee rights and labour costs incurred by employers.

The article also identifies the possible directions of research into the causes of varying PAL length, focusing on the dimensions of national cultures, based on Hofstede's model and legal tradition. Difficulties, however, stem from the limited number of countries covered by research on the dimensions of national cultures and the impact of supranational regulations. It is uncertain whether supranational regulations will facilitate the approximation of the PAL length, or the influence of national cultural determinants will exert a stronger impact.

In terms of PAL related changes, one can expect, on the one hand, a tendency towards longer PAL, on the other hand, however, the threat of an increase in the share of employees not covered by this type of entitlements is real. The expectation of PAL extension emerges mainly in European countries and in Australia. As shown above, PAL length is also reduced in individual cases. The future significance of PAL regulations may be affected by the implications of modern technology uses (especially communication platforms), reducing the traditional forms of employment and increasing the share of those who are self-employed or work under civil law contracts, but for one client only, performing gig work. The growth of this segment of the labour market poses a real threat that the number of PAL entitled employees will fall without granting them full privileges of the entrepreneur. The gig economy creates a potential area and a challenge for regulations developed by ILO and EU.

\section{Acknowledgment}

This research was funded by the University of Economics in Katowice, Faculty of Economics, Department of Economics, Sub department of Economic Systems statutory sources.

Author Contributions: The author confirms being the sole contributor of this work and approved it for publication. 
Conflict of Interest Statement: The author declares that the research was conducted in the absence of any commercial or financial relationships that could be construed as a potential conflict of interest.

\section{References}

Allen, T. D., Lapierre, L. M., Spector, P. E., Poelmans, S. A. Y., O’Driscoll, M., Sanchez, J. I., Coper, C. L., Walvoord, A. G., Antoniou, A. S., Brough, P., Geurts, S., Kinnunen, U., Pagon, M., Shima, S. \& Woo, J. M. (2014). The link between national paid leave policy and work-family conflict among married working parents. Applied Psychology: An International Review, 53(1), 5-28.

Altonji, J. G. \& Usui, E. (2007). Work hours, wages, and vacation leave. Industrial and Labor Relations Review, 60(3), 408-428.

Awanis, S., Schlegelmilch, B. B. \& Chi Cui, Ch. (2017). Asia's materialists: Reconciling collectivism and materialism. Journal of International Business Studies, 48(8), 964-991.

Bargain, O., Orsini, K. \& Peichl, A. (2014). Comparing labor supply elasticities in Europe and United States new results. Journal of Human Resources, 49(3), 723-838.

Beugelsdijk, S., Kostova, T. \& Roth, K. (2017). An overview of Hofstede-inspired country-level culture research in international business since 2006. Journal of International Business Studies, 48(1), 30-47.

Block, R. N., Park, J. Y. \& Kang, Y. H. (2013). Statutory leave entitlements across developed countries: Why US workers lose out on work-family balance. International Labor Review, 152(1), 125-143.

Botero, J. C., Djankov, R., Lopez-de-Silanes, F. \& Shleifer, A. (2004). The regulation of labor. World Bank.

Carincross, G. \& Waller, I. (2004). No taking annual leave: What could it cost Australia? Journal of Economic and Social Policy, 9(1), 1-17.

De Bloom, J. (2015). Making holidays work. Psychologist, 28(8), 632-636.

Eur-Lex.https://eur-lex.europa.eu/legal-content/PL/TXT/?uri=CELEX:32003L0088. (9.07.2018).

Fakih, A. (2018). What determines vacation leave? The role of gender. Bulletin of Economic Research, 70(1), 119.

Gereffi, G. (2014). On Richard M. Locke. The promise and limits of private power: Promoting labor standards in global economy, New York, Cambridge University Press, 2013. Socio-Economic Review, 12(1), 219-235.

Gilbert, D. \& Abdullah, J. (2002). A study of the impact of the expectation of holiday on an individual sense of well-being. Journal of Vacation Marketing, 8(4), 352-361.

Gregory, P. \& Stuart, R. (2004). Comparing Economic Systems in the twenty-first century. Houghton Mifflin Company: Boston-New York.

Hofstede, G., Hofstede, G. J. \& Minkov, M. (2010). Cultures and organizations. Software of the mind. New York, Chicago, San Francisco, Lisbon, London, Madrid, Mexico City, Milan, New Delhi, San Juan, Seoul, Singapore, Sidney, Toronto: Mc Graw Hill.

ILO. Conditions of Work and the Employment Programme http://www.ilo.org/dyn/travail/travmain.sectionReport1?p_lang=en\&p_structure=2\&p_sc_id=1368\&p_sc_id =1694\&p_sc_id=1390\&p_sc_id=1717\&p_countries (07.08.2018).

ILO. (1995). Conditions of work digest: Working time around the world. Geneva, Switzerland: International Labour Organization.

ILO. (2018). Women and men in the informal economy: A statistical picture, Geneva, Switzerland: International Labour Organization.

ILO. Normlex http://www.ilo.org/dyn/normlex/en/f?p=1000:12000:::NO:::(06.08.2018)

Jong, E. (2009). Culture and economics. On values, economics and international business. London and New York: Routlege Taylor and Francis Group.

Kinderman, D. (2017). Challenging varieties of capitalism's account of business interest. Socio-Economic Review, 15(3), pp. 587-613.

Kirkman, B. L., Lowe, K. B. \& Gibson, C. B. (2017). A Retrospective on culture's consequences: The 35-year journey. Journal of International Business Studies, 48(1), 12-29.

La Porta, R., Lopez-de-Silanes, F. \& Shleifer, A. (2008). The economic consequences of legal origins. Journal of Economic Literature, 46(2), 285-332.

Lee, S., Mc Cann, D. \& Messenger, J. (2007). Working time around the world. London and New York: Routlege Taylor and Francis Group.

Lindahl, M., Palme, M. \& Massih, S. S. (2015). Long-term intergenerational persistence of human capital on empirical analysis of four generations. Journal of Human Resources, 50(1), 1-33. 
Llewellyn Consulting (2016). Which countries in Europe offer the fairest paid leave and unemployment benefits? Glassdoor, Research Report.

Messenger, J. C. \& Ray, N. (2013). The Distribution of hours of work in developed and developing countries: What are the main differences and why? TRAVAIL Policy Brief, 5.

Minter, K. (2017). Negotiating labour standards in the gig economy: Airtasker and Unions New South Wales. The Economic and Labour Relations Review, 28(3), 438-454.

Oswald, A. J., Proto E. \& Sgroi, D. (2015). Happiness and productivity. Journal of Labor Economics, 33(4), 789822.

Ray, R. \& Schmitt, J. (2007). No-vacation nation USA - A comparison of leave and holiday in OECD countries. European Economic and Policy Brief, 3.

Ray, R. \& Schmitt, J. (2008). The right to vacation: An international perspective. International Journal of Health Services, 38(1), 21-45.

Skinner, N. \& Pockock, B. (2013). Paid annual leave in Australia: Who gets it, who takes it and implications for work-life interference. The Journal of Industrial Relations, 55(5), 681-698.

Stanford, J. (2017). The resurgence of gig work: Historical and theoretical perspective. The Economic and Labor Relations Review, 28(3), 382-401.

Steward, A. \& Stanford, J. (2017). Regulating work in the gig economy: What are the options? The Economic and Labor Relations Review, 28(3), 420-437.

Witt, M. A. \& Jackson, G. (2016). Varieties of Capitalism and institutional comparative advantage: A test and reinterpretation. Journal of International Business Studies, 47(7), 778-806.

Wooden, M. \& Warren, D. (2008). Paid annual leave and working hours: Evidence form the HILDA Survey. The Journal of Industrial Relations, 50(4), 664-670.

World Bank (2018). Doing Business 2018. Reforming to Create Jobs, Washington.

World Bank. (2019). Doing Business, Labor Market Regulation. http://www.doingbusiness.org/data/exploretopics/labor-market-regulation\#LMR-DB2015-DB-2019-servicesector-data-points-and-details (24.11.2018). 